\section{Impact of heat stress on Mytilus edulis: contaminants affect survival and HSP 70 proteoform expression}

\author{
R. Péden, ${ }^{1}$ J. Letendre, ${ }^{1}$ B. Rocher, ${ }^{1}$ \\ F. Durand, ${ }^{2}$ F. Le Foll, ${ }^{1}$ P. Chan, ${ }^{3}$ \\ D. Vaudry, ${ }^{4}$ F. Bultelle ${ }^{1}$
}

IUMR-I 02 INERIS-URCA-ULH

SEBIO/Unité Stress Environnementaux et BIOsurveillance des milieux aquatiques, Université du Havre; ${ }^{2}$ Faculty of Science, Le Havre University, Normandy University; ${ }^{3}$ Platform in proteomics PISSARO IRIB, Rouen University, Normandy University; ${ }^{4}$ Laboratories of Neuronal and Neuroendocrine Differentiation and Communication, INSERM U982, Rouen University, Normandy University, France

\section{Introduction}

The Intergovernmental Panel on Climate Change (IPCC 2007-13) has developed several models that all predict a rise in mean air temperatures over the next decades, associated with increases in temperature of coastal waters. ${ }^{1,2}$ The impact of these changes on coastal environments is in peculiar importance from an ecological and economical point of view. They shelter very high primary productive ecosystems, although abiotic conditions, such as tide intensity, temperature, oxygenation and salinity variations and biotic conditions, such as food availability are multiple constraints that represent limiting factors. Moreover, intertidal areas are severely impacted by complex pollutants cocktails linked to domestic effluent discharges, industrial and agricultural activities. Hence, the question is raised of the survival of organisms coping with an additional stress (temperature) that could reach their limit ability to adapt and compromise the population maintenance. By their wide distribution and direct exposure to abiotic and contamination stresses, sessile bivalves such as Mytilus edulis constitute good sentinel species in environmental studies. Their filterfeeding ability is a key characteristic as they bioaccumulate most chemicals associated to fine particles. Thus, blue mussels reflect local contamination history by integrating the environmental exposure.

During the last decades, proteomic tools have been used to compare responses of marine organisms in closely related populations to multiple environmental stresses in order to better understand cellular processes involved in the adaptive mechanisms. Thus, molecular chaperones constitute major actors and the role of HSP 70 has often been underlined. ${ }^{3}$ Gills are in peculiar interest because they represent a barrier between the outside aquatic environment and the whole body of the mussel and because of their implication in respiratory and feeding processes. In the present study, we focused on the Bay of the Seine River, a highly anthropized estuary (Eastern English Channel). We considered two contrasted locations in terms of pollution with a pristine site (Yport) and a highly polluted site (Le Havre). A proteomic approach to identify key proteins involved in temperature adaptations of mussels has been conducted in a laboratory stalling system. This system reproduced intertidal and diurnal variations with a combination of different temperature conditioning followed by a single acute thermal stress. We particularly studied the impact of pre-conditioning on mussel mortality rate and HSP 70 proteoform expression.

\section{Materials and Methods}

\section{Sample collection and microcosm exposition}

Adult mussels (shell length $37.5 \mathrm{~mm}+/-3$
Correspondence: Romain Péden, Laboratory of Ecotoxicology, UMR-I 02 INERIS-URCA-ULH SEBIO, Le Havre University, Normandy University, France.

E-mail: romain.peden@univ-lehavre.fr

Key words: proteomics, mussel, acclimation, heat shock response, mortality.

Acknowledgments: Romain Péden was a recipient for a doctoral fellowship from the Communauté De l'Agglomération Havraise (CODAH).

This work is licensed under a Creative Commons Attribution NonCommercial 3.0 License (CC BYNC 3.0).

(C) Copyright R. Péden et al., 2014

Licensee PAGEPress, Italy

Journal of Xenobiotics 2014; 4:4892

doi:10.4081/xeno.2014.4892

$\mathrm{mm}, \mathrm{n}=540$ ) were collected during July 2013 in tidal zone of the reference site La Pointe $d u$ Chicart, Yport $\left(49^{\circ} 44^{\prime} 28^{\prime \prime} \mathrm{N}, 0^{\circ} 17^{\prime} 53^{\prime \prime} \mathrm{E}\right.$, water temperature $15^{\circ} \mathrm{C}$ ) and the contaminated site Cap de la Hève, Le Havre $\left(49^{\circ} 30^{\prime} 41^{\prime \prime} \mathrm{N}\right.$, $0^{\circ} 3$ ' 56 ' $\mathrm{E}$, water temperature $\left.16^{\circ} \mathrm{C}\right)$. For each site, twenty mussels were directly dissected and gills snap frozen in liquid nitrogen consti-

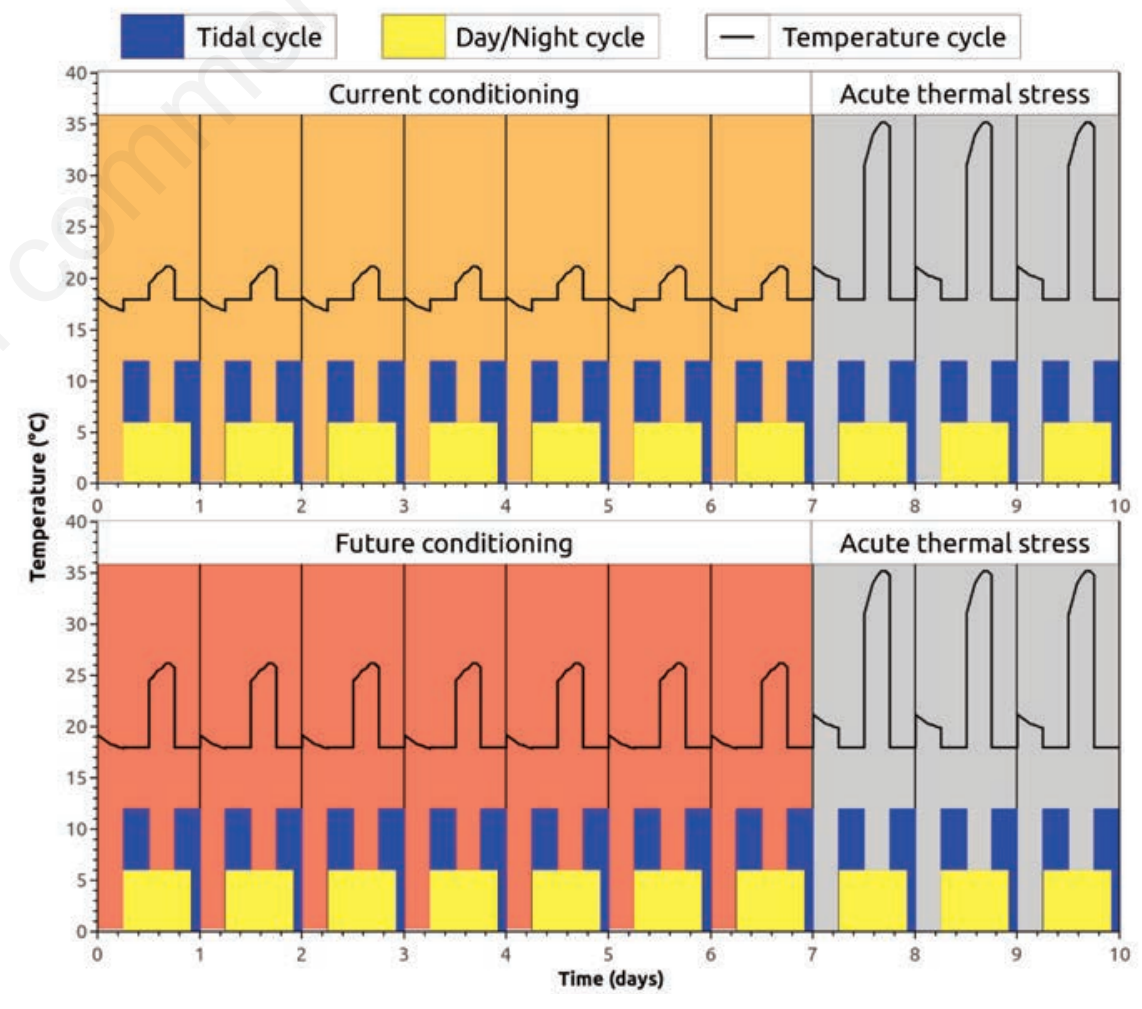

Figure 1. Tidal, day/night and temperature cycles setting in microcosm exposition. Mussels were exposed in parallel for 7 days to present temperature (current conditioning) or to higher temperature (future conditioning). Then, both groups were exposed to an identical acute thermal stress for 3 days. 
tuting control group (C). The other mussels were randomly split in two climatic chambers reproducing tidal variations and diurnal cycles (Figure 1). Animals were fed daily with Shellfish Diet 1800 (Reed Mariculture). Prior to thermal exposition, mussels were acclimated to setting water temperature $\left(18^{\circ} \mathrm{C}\right)$ by $1^{\circ} \mathrm{C} /$ day steps. Then, mussels were exposed for 7 days either to present thermal conditions (group A) or to predict future conditions (group F) as defined in A1B IPCC scenario. ${ }^{1}$ Finally, both groups were exposed to identical acute thermal stress for 3 days. In each group, 48 mussels were sacrificed at day 7 and 10 and gills were dissected and snap frozen.

\section{Mortality monitoring}

The progression of mussel mortality was followed by daily observations. Dead animals were removed and not replaced. Mortality was calculated after 7 days and after 10 days exposure (end-point) and expressed as percentage of remaining mussels in stalling system.

\section{Proteomic analysis}

Two-dimensional electrophoresis (2DE) was performed on end-point mussels (groups A and F) versus control mussels (group $\mathrm{C}$ ). Protocol was adapted from Letendre et al. ${ }^{4}$ Briefly, gill proteins were extracted by Precellys grinding in $50 \mathrm{mM}$ Tris buffer $\mathrm{pH} 7.8$ containing urea 9M, CHAPS 2\%, DTE $65 \mathrm{mM}, 0.8 \%$ pharmalytes $\mathrm{pH} 3-10$. The homogenate were sonicated $30 \mathrm{~s}$ in 3" Cup-Horn (Maximum power: 100\%, Qsonica) and centrifuged at $10,000 \mathrm{~g}, 20^{\circ} \mathrm{C}$ for $20 \mathrm{~min}$. Protein contents were measured in supernatant according to the method of Bradford with bovine serum albumin as a standard. For isoelectrofocusing, $750 \mu \mathrm{g}$ of proteins were loaded on pH 3-10NL strips. Eight biological replicates were performed for each group (total number of gels by site=24). After blue colloidal staining, gels were scanned using the GS-800 ${ }^{\mathrm{TM}}$ Calibrated Densitometer (Bio-Rad), exported from Quantity One as raw file (16bits, .tif), processed and statistically analyzed using Delta2D (DECODON GmbH).

\section{Results and Discussion}

\section{Mortality}

No mortality was observed for animals from both sites after laboratory conditioning. Mortality below 5\% was measured in both groups after the 7 days of acclimation. For Yport, death rate remained under 5\% at the end of the acute stress (end-point). However, mussel originating from Le Havre exhibited differential survivals depending on the conditioning scenario. Thus, individuals acclimated to future temperature showed moderate mortality (8.3\%) whereas those acclimated to pres-

\begin{tabular}{|c|c|c|c|c|}
\hline \multicolumn{2}{|c|}{ Mortality (\%) } & $\begin{array}{c}\text { After laboratory } \\
\text { conditioning }\end{array}$ & $\begin{array}{c}\text { After acclimation } \\
\text { (+7 days) }\end{array}$ & $\begin{array}{c}\text { After acute thermal } \\
\text { stress (+10 days) }\end{array}$ \\
\hline \multirow{2}{*}{ LE HAVRE } & Group A & $\mathbf{0} \%$ & $\mathbf{1 . 8} \%$ & $\mathbf{5 1 . 7} \%$ \\
& Group F & $0 \%$ & $1.8 \%$ & $\mathbf{8 . 3} \%$ \\
\hline \multirow{2}{*}{ YPORT } & Group A & $\mathbf{0} \%$ & $4.3 \%$ & $\mathbf{3 . 5} \%$ \\
\hline & Group F & $0 \%$ & $4.3 \%$ & $\mathbf{2 . 3} \%$ \\
\hline
\end{tabular}

Percentages of mortality were expressed as the ratio of dead mussels on remaining animals.

Figure 2. Mortality progression among sites and groups.
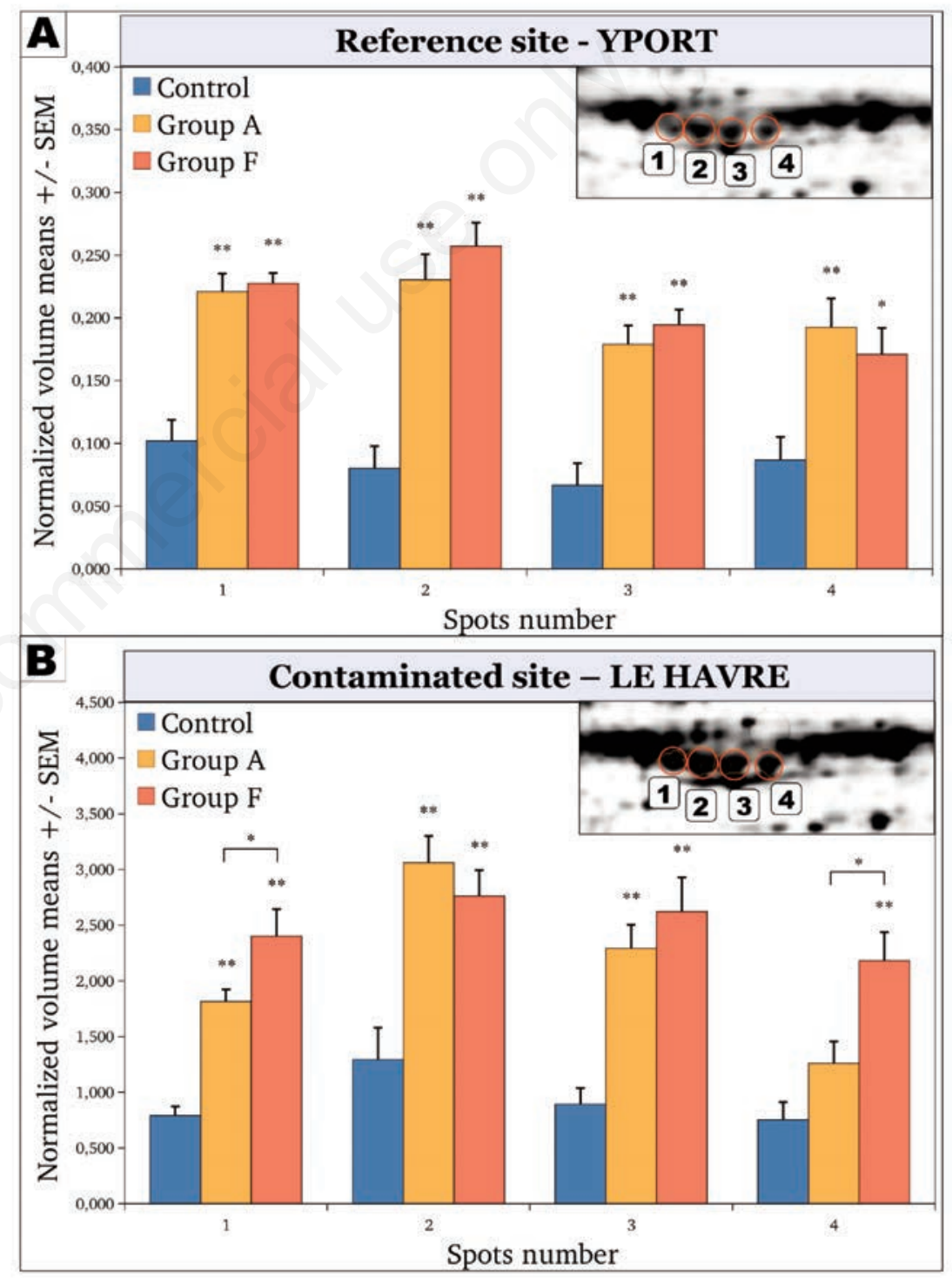

Figure 3. Focus on HSP 70 pattern. Four spots corresponding to HSP 70 proteoforms (upper right corner) were detected and individually compared between three conditions (C: control, A: present thermal conditions and F: predicted future conditions) and two sites: Yport (A) and Le Havre (B). Results are expressed as mean of normalized volumes \pm SEM, $n=8$. Differences between conditions were tested using Student $t$-test $\left({ }^{* *} \mathbf{P}<0.01,{ }^{*} \mathbf{P}<0.05\right)$. 
ent temperature exhibited over $50 \%$ of death rate (Figure 2). So, animals exposed to low level of pollution (Yport) demonstrate a good thermal resistance even when dealing with an acute thermal stress. In contrast, in mussels originating from a highly polluted area (Le Havre), this resistance seems to pass a threshold when a rapid and acute thermal stress occurred. In this case, the energy allocated to withstand to xenobiotics may encroach that required for acute thermal stress resistance. Hence, in case of gradually increase in temperature, on a scale century for instance, mussels could attempt to develop mechanisms of heat stress resistance whereas a rapid transition could overwhelm their capacity of survival, especially in polluted contexts.

\section{Heat Shock Protein 70 expression}

We focused our study on a narrow area of 2DE gels where spots were previously identified as HSP 70 proteoforms. ${ }^{4}$ We confirmed this identification by mass spectrometry analysis (data not shown). Four spots were discriminated and for each one and each replicate, normalized volumes were calculated. Means of normalized volumes were compared between groups (C, A and F) for Yport (Figure $3 \mathrm{~A})$ and Le Havre (Figure 3B). For each site, results showed an over-expression of HSP 70 proteoforms in $\mathrm{A}$ and $\mathrm{F}$ groups compared to control groups, except for one spot at Le Havre (spot 4). In accordance with literature, the HSP 70 levels markedly increased after heat stress in mussels living in temperate intertidal area., ${ }^{3,5,6}$ For pristine site, an over-expression of roughly 2.5 -fold was observed for all proteoforms. In this case, the acclimation did not impact the induction of HSP 70. At the opposite, for Le Havre site, the overall pattern showed a more complicated response with 2 spots exhibiting a lower HSP 70 inducibility in animals from group A (spot 1 and 4). Indeed, proteoform 4 did not show any difference between A and control conditions. We therefore hypothesize on a possible inhibiting effect of pollution on HSP 70 induction. Contamination generates oxidative stress, which in turn could impact with HSP 70 synthesis. ${ }^{7}$ Furthermore, it is known that heat shock response, including HSP 70 synthesis, constitutes an important part of the dynamic energy budget in Mytilus gender. ${ }^{8,9}$ Thus, the energy consumption needed to face thermal stress could once more be in competition with energy allocated to xenobiotic response.

\section{Conclusions}

As a conclusion this study reinforces that complex surrounding chemical pollution is able to alter HSP 70 induction and impact survival of animals submitted to acute thermal stress. This highlights that individuals may response differently to thermal stress according to their thermal history. Hence, thermal acclimation will play a major role in the survival of mussel populations in a global warming context.

\section{References}

1. Pachauri RK, Reisinger A. Climate Change 2007: Synthesis Report. Contribution of Working Groups I, II and III to the Fourth Assessment Report of the Intergovernmental Panel on Climate Change. Cambridge: Cambridge University Press; 2007.

2. Stocker TF, Qin D, Plattner GK, Tignor M, Allen SK, Boschung J, et al. Climate Change 2013: The Physical Science Basis.
Contribution of Working Group I to the Fifth Assessment Report of the Intergovernmental Panel on Climate Change. Cambridge: Cambridge University Press; 2013.

3. Tomanek L. Proteomics to study adaptations on marine organisms to environmental stress. J Proteomics 2014;105:92106.

4. Letendre J, Dupont-Rouzeyrol M, Hanquet AC, Durand F, Budzinski H, Chan P, et al. Impact of toxicant exposure on the proteomic response to intertidal condition in Mytilus edulis. Comparat Biochem Physiol Part D Genom Proteom 2011;6:357-69.

5. Chapple JP, Smerdon GR, Berry RJ, Hawkins AJS. Seasonal changes in stress70 protein levels reflect thermal tolerance in the marine bivalve Mytilus edulis L. J Exp Marine Biol Ecol 1998;229:53-68.

6. Buckley BA, Owen ME, Hofmann GE. Adjusting the thermostat: the threshold induction temperature for the heat-shock response in intertidal mussels (genus Mytilus) changes as a function of thermal history. J Exp Biol 2001;204:3571-9.

7. Spiró Z, Arslan MA, Somogyvári M, Nguyen MT, Smolders A, Dancsó B, et al. RNA Interference Links Oxidative Stress to the Inhibition of Heat Stress Adaptation. Antioxid Redox Signal 2012;17:890-901.

8. Hawkins AJS. Relationships between the synthesis and breakdown of protein, dietary absorption and turnovers of nitrogen and carbon in the blue mussel, Mytilus edulis L. Oecologia 1985;66:42-9.

9. Anestis A, Lazou A, Pörtner HO, Michaelidis B. Behavioral, metabolic, and molecular stress responses of marine bivalve Mytilus galloprovincialis during long-term acclimation at increasing ambient temperature. Am J Physiol Regul Integr Comparat Physiol 2007;293:911-21. 